\title{
Does income matter for troublesome neck pain? A population-based study on risk and prognosis
}

\author{
Lina Palmlöf, ${ }^{1}$ Eva Skillgate, ${ }^{1,2}$ Lars Alfredsson, ${ }^{1}$ Eva Vingård, ${ }^{3}$ Cecilia Magnusson, ${ }^{4}$ \\ Michael Lundberg, ${ }^{4}$ Lena W Holm ${ }^{1}$
}

1 Institute of Environmental Medicine, Karolinska Institutet, Stockholm, Sweden

${ }^{2}$ Scandinavian College of Naprapathic Manual Medicine,

Stockholm, Sweden

${ }^{3}$ Occupational and

Environmental Medicine

Department of Medical Science,

Uppsala University, Uppsala

Sweden

${ }^{4}$ Division of Public Health

Epidemiology, Department of

Public Health Sciences,

Karolinska Institutet, Stockholm,

Sweden

\section{Correspondence to}

Lina Palmlöf, Institute of

Environmental medicine,

Karolinska Institutet, Box 20,

Solna 177 71, Sweden; lina

palmlof@ki.se

Accepted 28 January 2012

Published Online First

3 December 2012

\section{ABSTRACT}

Background Studies have shown associations between higher income and better health, but income has not been studied in relation to neck pain. The aims of this cohort study were to assess the sex-specific role of disposable income for onset and prognosis of neck pain in the general population and if economic stress influences such potential associations.

Methods Two subcohorts were identified in the Stockholm Public Health Cohort with data from 2002. Cohort I (risk cohort) included persons without neck pain $(n=8348)$. Cohort II (prognostic cohort) included persons with occasional neck pain during the previous 6 months $(n=10523)$. Both cohorts were assessed for long duration troublesome neck pain (LDNP) in 2007. Individual income was defined as aggregated annual family income in 2002 with each family member assigned a weighted consumption share, based on salary, pensions and social benefits. LDNP in 2007 was defined as having had troublesome neck pain lasting for three or more consecutive months the previous 5 years. Association between income and LDNP, considering potential confounding, was investigated by multivariable logistic regression. Economic stress was tested as effect modifier between income and LDNP.

Results In both cohorts, associations were found between lower income and a higher risk for LDNP. The results were similar between the sexes. Economic stress modified the associations in both cohorts.

Conclusions Low income may be a risk as well as prognostic factor for developing LDNP. Furthermore, the results indicate that economic stress may be an underlying factor to consider when studying associations between income and neck pain.

\section{INTRODUCTION}

Neck pain is a common health problem in the general and working population with a 12-month prevalence of $27 \%-50 \%$, and the condition is recurrent within $1-5$ years in $50 \%-75 \%$ of the cases. $^{1-3}$

According to the most recent systematic review, older age, worse prior health and smoking increase the risk for developing neck pain. ${ }^{1}$ The authors also found that psychological and social factors play an important role, although further research is needed. Gender has been studied, however, without consistency in the results. ${ }^{1}$

Regarding prognostic factors for recovery of neck pain, Carroll et al ${ }^{\beta}$ found that younger age predicts better recovery in the general population, while research on the role of gender has given inconsistent results. The same study showed that psychological and social factors, such as coping strategies and social support, affect the course of neck pain. In a working population, Bergstrom et $a l^{4}$ studied occupational class, concluding that white-collar as opposed to blue-collar workers have a better chance of recovery, although physical workload seemed not to affect the outcome. However, Holtermann et al demonstrated that a heavier physical workload negatively affects the prognosis for long-term sickness absence. Also, high pain intensity predicted long-term sickness absence in the same study.

Neck pain has been showed to be associated with depressive mood. ${ }^{6}$ Several previous studies have assessed income and other determinants of socioeconomic position in relation to depression and psychological distress. ${ }^{8-10}$ Kosidou et al ${ }^{8}$ investigated possible associations between individual disposable income and risk for onset of psychological distress, severe psychological distress and depression, respectively. Their findings indicated an association with income and that it may be more pronounced in women.

Income is often considered when studying the effect of social position on general health. When studying how income affects health in the USA and Canada, it was evident that health improves with higher income. ${ }^{11}$ Also depression was affected by income, with a negative relationship between grade of depression and increasing income.

Strong associations have been found between high household income, as well as wealth, and good self-rated health. ${ }^{12}$ No gender differences were detected in the associations for household income, although the association between wealth and selfrated health was weaker among men. The association between household income and general health, as well as household income and depression, lead us to question whether it may be associated with other disorders as well. The ambiguity in the study results concerning whether sex is modifying the associations between income and health motivated us to explore this further.

Studying income in relation to health requires consideration of what aspects of income that would possibly give ill health. Stress is a phenomenon likely to be linked with economy. High stress levels are associated with muscle pain ${ }^{13}$ and therefore also neck pain.

The aims of this cohort study were to assess the sex-specific role of disposable income for onset and prognosis of neck pain in the general population and if economic stress influences such potential associations. 


\section{METHODS}

\section{Recruitment and participants}

This longitudinal study is based on the Stockholm Public Health Cohort (SPHC) $(n=23794)$. The source population was residents 18-84 years old, living in Stockholm County, Sweden, an urban region including 24 municipalities with approximately 1.4 million inhabitants (2002). A sample of 50067 residents were randomly selected after stratification for gender and residential area. Between October 292002 and March 22 2003, they were contacted with an extensive baseline questionnaire, with a maximum of three reminders. A follow-up questionnaire was sent between March 14 and August 15, 2007. Both questionnaires included, among others, questions regarding demographic and socioeconomic characteristics and physical and psychological health. Additional data, for example, disposable income and employment, were retrieved from Swedish national registers. ${ }^{14} 15$

Two subcohorts were identified based on the presence of neck pain at baseline in 2002-2003. For the assessment of risk for onset of long duration troublesome neck pain (LDNP), the cohort was based on individuals who reported no neck pain during the past 6 months $(\mathrm{n}=8348)$ (cohort I, free from neck pain). For the assessment of prognosis of neck pain, the cohort was based on adults with occasional neck pain, that is, those reporting that they have had neck pain up to a couple of days per month during the past 6 months $(n=10523)$ (cohort II, occasional neck pain) (figure 1).

\section{Definitions}

Individual disposable income

Annual individual disposable income was calculated based on the aggregated annual household income in year 2002. All taxable income (wage earnings, complementary social allowances, pension), as well as final tax deductions, are taken into account in the household income. The household income was then individualised by multiplying it by the individual's assigned consumption weight and dividing it by the total consumption weight of the family members. The final individual disposable income are net values, given in Swedish kroner (SEK) (100 SEK are approximately $€ 10,67)$.

The variable individual disposable income was grouped in quartiles, 0-115299 SEK (€0-12 302), 115300-154 199 SEK (€12 303-16 453), 154 200-207499 SEK (€164 54-22 140) and $\geq 207500$ SEK ( $€ \geq 22141$ ). This categorisation was made for

Figure 1 Flowchart of inclusion process for the study.

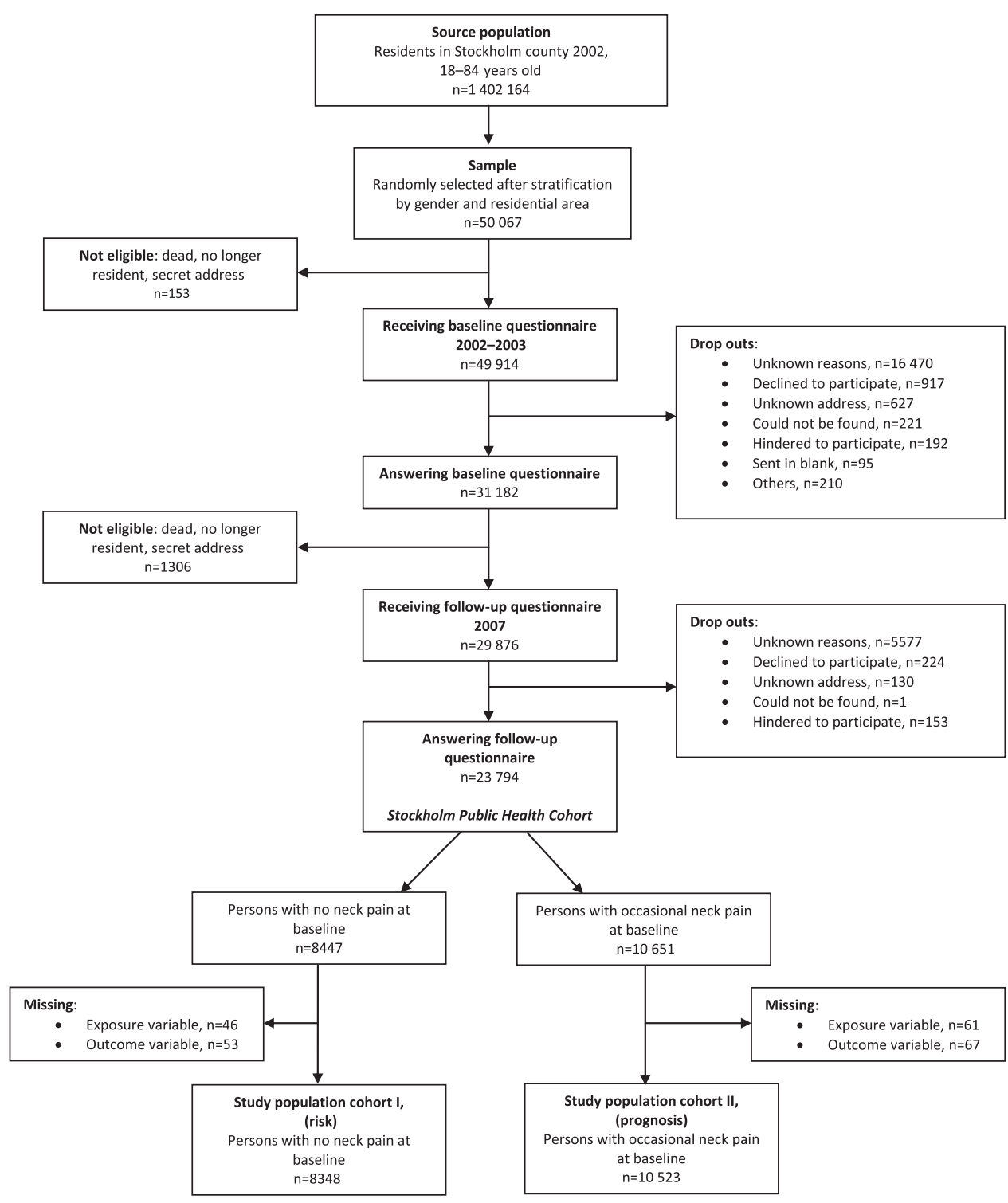




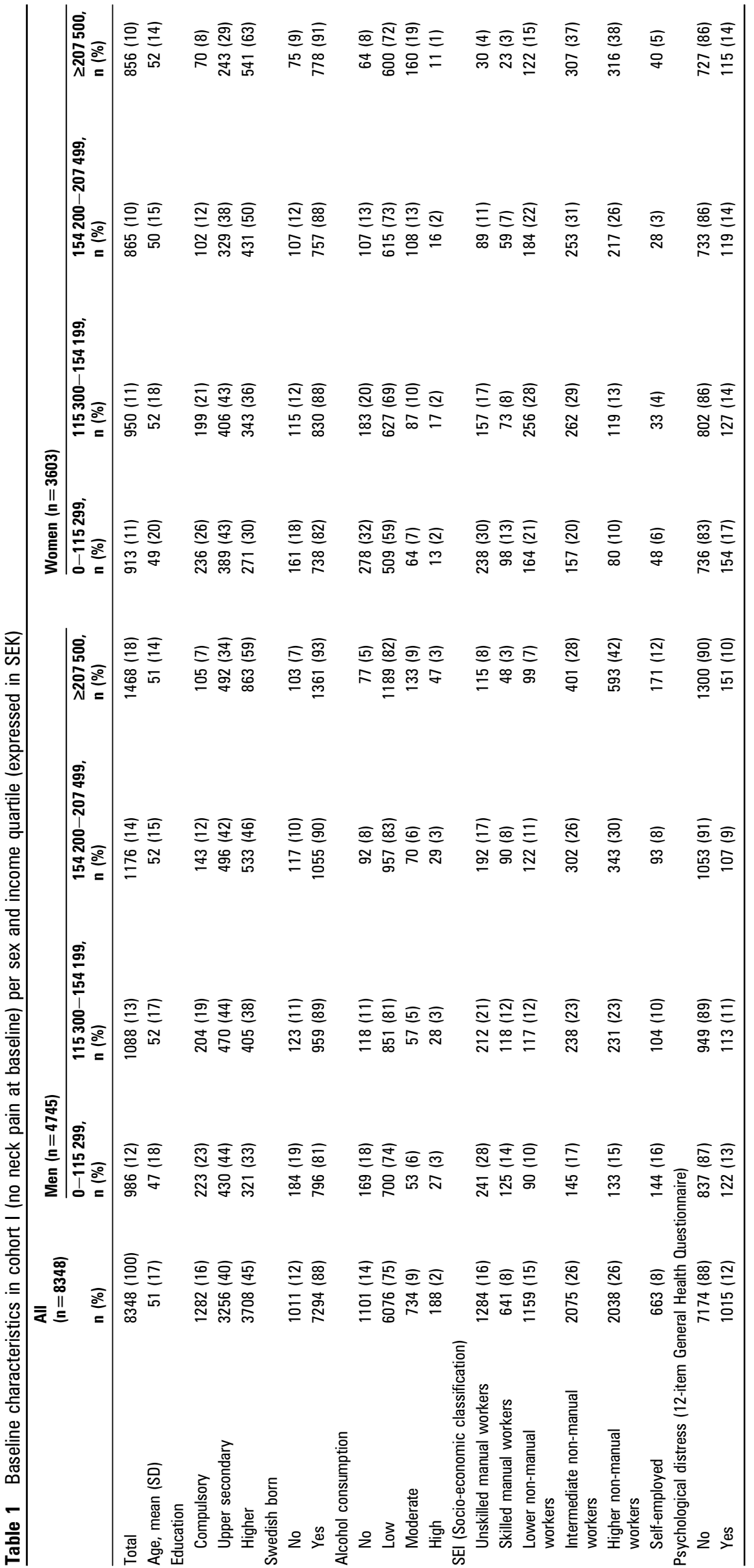


the whole cohort ( $\mathrm{n}=23974)$, thus the distribution within the strata in our analytical samples (cohorts I and II) differ to some extent.

\section{Outcomes}

The following operationalisation of LDNP was used: in 2007 having answered 'yes' to the following question: "During the past five year period, have you had neck pain that lasted at least three consecutive months that disturbed you considerably?"

The time frames for durations of neck pain are in accordance with the suggestions from the Bone and Joint Neck Pain Task Force. ${ }^{16}$ In this study, we use the definition LDNP defined as bothersome neck pain that lasted 3 months or more. This was the outcome in both cohorts.

\section{Potential confounders and effect modifier}

We used information from the survey in 2002-2003 when choosing potential confounders. The choice was guided by knowledge of risk and prognostic factors for neck pain. ${ }^{1-3} 17 \mathrm{We}$ considered the following factors to potentially confound the association between disposable income and the outcome: immigrant status (born in or outside of Sweden), alcohol consumption (expressed in gram of $100 \%$ alcohol per day and categorised into no, low, moderate and high level of consumption), smoking (never, ever or current smoker), concurrent low back pain (during the past 6 months measured on a 5-level Likert scale ranging from 'never' to 'daily') and physical activity during leisure time (four categories from mainly sedentary activity with less than $2 \mathrm{~h}$ of light physical activity up to regular activity at least three times per week for at least 30 min sessions). We also tested for week hours of household work and physical occupational workload (measured on a 4-level Likert scale anchoring sedentary to heavy work). The baseline questionnaire contained some of the questions from the Job Content Questionnaire, concerning psychosocial occupational workload. ${ }^{18}$ Of the available questions, we chose to test two: freedom to decide how the work shall be performed and freedom to decide what should be performed. Furthermore, we tested for levels of psychological distress (measured by the 12 -item General Health Questionnaire). ${ }^{19}$ A sum score of $\geq 3$ (using the recommended standard 0 0-1-1 scoring on the four answering alternatives) was used to denote psychological stress.

Due to the potential presence of effect measure modification by economic stress on the association between income level and LDNP, we used the response to the following question to address this, "Did it during the previous 12 months happen that you ran out of salary/money and that you had to borrow from relatives and friends to be able to pay for food or rent?". Answering 'yes' to this question was defined as having been exposed to economic stress.

\section{Statistical analysis}

We used multivariable logistic regression to assess the association between the exposure and the outcomes. We built four different models based on gender and the outcome. We determined the role of possible confounders for each of these models, by including the potential confounding factors, one at a time. If a factor changed the crude estimate by more than $10 \%$, it was entered in the final model. All analyses were adjusted for age. When conducting confounding control, the exposure was dichotomised based on the median.

To test the effect modification of economic stress, we combined income level and economic stress in a dummy variable, where the reference group was set to those without economic stress and having an income corresponding to the second, third or fourth quartile ( $\geq 115300$ SEK). Due to risk of low power, we adjusted for sex instead of stratifying. Also included were the factors that were adjusted for in the main analysis.

Results are presented as crude and adjusted ORs with 95\% CIs. Statistical analyses were run with $\mathrm{SAS} \circledast$ statistical software system V.9.1 and STATA® statistical software system V.11.

\section{RESULTS}

\section{Individual disposable income and LDNP}

\section{Cohort I (risk)}

A description of the study participants who were free of neck pain in 2002 and included in cohort I is shown in table 1.

In table 2 , the crude and adjusted sex-specific ORs are presented. Few factors were found to confound the association between level of income and onset of neck pain. In men, none of the factors tested confounded the association between income level and onset of neck pain, whereas in women, level of alcohol consumption slightly reduced the ORs across the income levels.

For men, the adjusted estimate showing the strongest association was found in the lowest income category (OR 1.8, 95\% CI 1.1 to 2.8). Women in the lowest and second lowest category of income had an adjusted OR of 1.6 (95\% CI 1.0 to 2.6$)$ and 1.7 (95\% CI 1.0 to 2.7 ), respectively. No difference in risk for LDNP could be seen in the second highest category of income compared with the highest.

\section{Cohort II (prognosis)}

Table 3 presents a description of the study participants included in cohort II, that is, those who had reported occasional neck pain at baseline.

Table 4 presents the crude and adjusted sex-specific ORs of the association between income level and reporting at least one episode of LDNP during the follow-up period.

As in cohort I, few factors confounded the association between income level and LDNP. Adding age to the models did

Table 2 Association between individual disposable income and long duration troublesome neck pain in cohort I (no neck pain at baseline), presented with ORs

\begin{tabular}{|c|c|c|c|c|c|}
\hline \multirow[b]{2}{*}{$\begin{array}{l}\text { Individual disposable income } \\
\text { (Swedish kroner/year) }\end{array}$} & \multirow[b]{2}{*}{$\begin{array}{l}\text { Cases/ } \\
\text { non-cases }\end{array}$} & \multicolumn{2}{|l|}{ Men $(n=4745)$} & \multicolumn{2}{|c|}{ Women $(n=3603)$} \\
\hline & & $\begin{array}{l}\text { Crude OR } \\
(95 \% \mathrm{CI})\end{array}$ & $\begin{array}{l}\text { Adjusted OR* } \\
(95 \% \mathrm{Cl})\end{array}$ & $\begin{array}{l}\text { Crude OR } \\
(95 \% \text { CI) }\end{array}$ & $\begin{array}{l}\text { Adjusted OR } \dagger \\
(95 \% \mathrm{CI})\end{array}$ \\
\hline$\geq 207500$ (ref) & $66 / 2252$ & 1 & 1 & 1 & 1 \\
\hline $154200-207499$ & $59 / 1968$ & $1.0(0.6$ to 1.7$)$ & $1.0(0.6$ to 1.7$)$ & $1.0(0.6$ to 1.8$)$ & $1.0(0.6$ to 1.7$)$ \\
\hline $115300-154199$ & $91 / 1930$ & $1.3(0.8$ to 2.0$)$ & 1.3 (0.8 to 2.0$)$ & 1.9 (1.2 to 3.0$)$ & $1.7(1.0$ to 2.7$)$ \\
\hline $0-115299$ & $105 / 1780$ & 1.8 (1.1 to 2.7$)$ & 1.8 (1.1 to 2.8 ) & 2.0 (1.2 to 3.1$)$ & $1.6(1.0$ to 2.6$)$ \\
\hline
\end{tabular}

${ }^{*}$ Adjusted for age.

†Adjusted for age and alcohol consumption. 


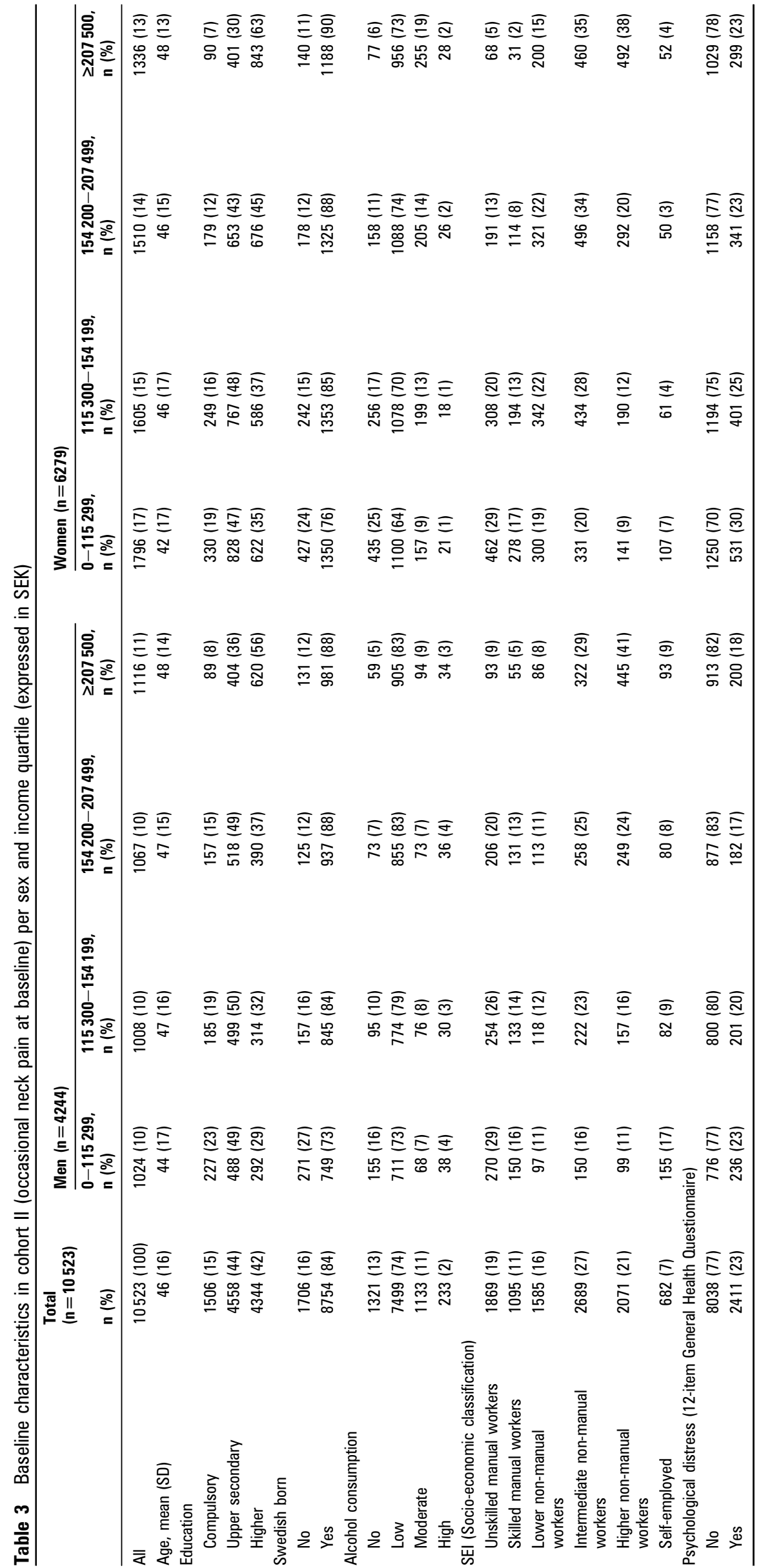


Table 4 Association between individual disposable income and long duration troublesome neck pain in cohort II (occasional neck pain at baseline), presented with ORs

\begin{tabular}{|c|c|c|c|c|c|}
\hline \multirow[b]{2}{*}{$\begin{array}{l}\text { Individual disposable income } \\
\text { (Swedish kroner/year) }\end{array}$} & \multirow[b]{2}{*}{$\begin{array}{l}\text { Cases/ } \\
\text { non-cases }\end{array}$} & \multicolumn{2}{|l|}{ Men $(n=4244)$} & \multicolumn{2}{|c|}{ Women $(n=6279)$} \\
\hline & & $\begin{array}{l}\text { Crude OR } \\
(95 \% \text { CI) }\end{array}$ & $\begin{array}{l}\text { Adjusted OR* } \\
(95 \% \mathrm{Cl})\end{array}$ & $\begin{array}{l}\text { Crude OR } \\
(95 \% \mathrm{CI})\end{array}$ & $\begin{array}{l}\text { Adjusted OR } \dagger \\
(95 \% \mathrm{CI})\end{array}$ \\
\hline$\geq 207500$ (ref) & $229 / 2209$ & 1 & 1 & 1 & 1 \\
\hline $154200-207499$ & $261 / 2301$ & $1.0(0.8$ to 1.4$)$ & $1.0(0.8$ to 1.4$)$ & $1.1(0.9$ to 1.4$)$ & $1.1(0.9$ to 1.4$)$ \\
\hline $115300-154199$ & $292 / 2311$ & $1.2(1.0$ to 1.7$)$ & 1.2 (0.9 to 1.6$)$ & $1.2(1.0$ to 1.5$)$ & $1.2(1.0$ to 1.5$)$ \\
\hline $0-115299$ & $372 / 2420$ & $1.6(1.2$ to 2.1$)$ & $1.6(1.2$ to 2.1$)$ & $1.4(1.1$ to 1.8$)$ & $1.3(1.0$ to 1.6$)$ \\
\hline
\end{tabular}

${ }^{*}$ Adjusted for age.

†Adjusted for age and immigrant status.

not change the estimates. In women, adding immigrant status slightly attenuated the associations. In men, no factors were found to confound the associations.

The strongest associations were found in the lowest category of income, with an adjusted OR of 1.6 (95\% CI 1.2 to 2.1$)$ for men and 1.3 (95\% CI 1.1 to 1.6) for women. In the higher categories of income, no associations were found.

\section{Analysis of effect measure modification}

The results of the effect measure analyses with income and economic stress as combined exposure are shown in table 5.

\section{Cohort I}

The results showed a weak association in those with only one of the exposures present. Low income without economic stress gave an OR of 1.3 (95\% CI 1.0 to 1.7). For those who had experienced economic stress but did not belong to the lowest quartile of income, the corresponding OR was 1.2 (95\% CI 0.7 to 2.1). Having both exposures, however, was associated with a twofold increase in the odds of getting LDNP (OR 2.0, 95\% CI 1.3 to 3.2). This slightly exceeds the combined increase of the odds in those with either of the exposures present, thus indicating that the two factors interact in the development of LDNP.

\section{Cohort II}

Similar to the results in cohort I, those with economic stress not belonging to the lowest quartile of income had slightly increased odds of having LDNP compared with the reference group (OR 1.3, 95\% CI 1.0 to 1.6). OR for those with low income and without economic stress was 1.1 (95\% CI 0.9 to 1.3), while those with both exposures present had an OR of 1.8 (95\% CI 1.4 to 2.2) of getting LDNP compared with the reference group. Also in this cohort, the odds of those with both exposures present slightly exceed the combined increase of the odds in those with either of the exposures present.

\section{DISCUSSION}

In studying the association between level of disposable income and LDNP, we found that those in the lowest income category seems to have a higher risk of getting LDNP, regardless if they were free from neck pain or if they had occasional neck pain at baseline. The associations could not be explained by factors concerning lifestyle or occupational physical or psychosocial strain.

The results from both cohorts indicated that the individual disposable income and economic stress might interact regarding risk of LDNP.

There are several different ways of defining income in studies on its relation to health. Three frequently used definitions are individual income, household income and wealth. In a study by Martikainen et $a l,{ }^{20}$ household income and wealth gave more consistent results when adjusting for pre-existing health, sociodemographic factors and other measures of social position. These results support our choice of exposure, which is calculated from household income and not solely based on individual income.

When studying a possible association between income and health, it is necessary to consider the different aspects within the concept of income and economy. In a country like Sweden, with a variety of publically provided services and a welfare system that is considered to have a high standard, the concept of poverty does not exist in the meaning of not having access to food, water and healthcare. However, according to Marmot, ${ }^{11}$ there is another aspect of poverty which can be seen in developed countries that can still affect health, namely possibilities for social participation. Considering poverty in this meaning includes not being able to take your family for a vacation or conducting a certain leisure time activity. This form of poverty may have an effect on our results, as it is probably a part of the concept of economic stress as defined in this study.

It seems that the association between income and neck pain is not only due to the possibilities to consume goods or services. Since economic stress was present even in those with higher income and those also had a higher odds for LDNP compared with those without economic stress, conjecturally the effect of individual disposable income on the risk of getting LDNP, as seen in this study, is somewhat due to the stress of not being able to manage your economy irrespective of income level.

Table 5 Associations between different combinations of exposures (income and economic stress) and long duration troublesome neck pain, presented with ORs

\begin{tabular}{|c|c|c|}
\hline Combination of exposures & $\begin{array}{l}\text { Cohort I, no neck pain at } \\
\text { baseline } \\
\text { Adjusted } 0 \mathrm{R}^{*}(95 \% \mathrm{Cl})\end{array}$ & $\begin{array}{l}\text { Cohort II, occasional neck } \\
\text { pain at baseline } \\
\text { Adjusted } 0 \mathrm{R} \dagger(95 \% \mathrm{CI})\end{array}$ \\
\hline $\begin{array}{l}\text { Income quartile 2-4, no economic } \\
\text { stress (ref) }\end{array}$ & 1 & 1 \\
\hline Income quartile $2-4$, economic stress & $1.2(0.7$ to 2.1$)$ & $1.3(1.0$ to 1.6$)$ \\
\hline Income quartile 1 , no economic stress & $1.3(1.0$ to 1.7$)$ & $1.1(1.0$ to 1.3$)$ \\
\hline Income quartile 1, economic stress & $2.0(1.3$ to 3.2$)$ & $1.8(1.4$ to 2.2$)$ \\
\hline
\end{tabular}


Social factors are known risk factors for neck pain, ${ }^{1}$ and potentially the results from this study are effects of the same phenomenon, that is, that the lower possibility of social participation due to income gives a higher risk for LDNP. Another suggestive explanation is that the physiological stress reaction per se gives the increased risk for LDNP. Long-term stress is believed to affect muscles through several potential mechanisms, resulting in pain. ${ }^{13}$

Sweden is a country with many registers of high quality. The registers of income, social benefits and pensions, used in the present study, are related to the tax system and can therefore be expected to be among the most accurate. Individual disposable income, as defined in this study, is well defined and based on register information. This entails accuracy in measurement, which is very high, resulting in a risk of exposure misclassification that is negligible. However, the risk of specifying the exposure improperly is somewhat increased by the fact that the categorisation of income was made in quartiles, not taking any real-life threshold values of economic decency or wealth into account.

The data from the SPHC is rich and contains information on a wide variety of domains. This enables an extensive analysis of confounding which vouches for high internal validity, although we cannot rule out unmeasured or residual confounding.

There was a loss to follow-up of $20 \%$ in this study. According to Pizzi et al, the possible bias introduced to the exposuredisease associations in a study due to restricted sample, such as a cohort study, is only weak. ${ }^{21}$ And for selection bias to affect our results, neck pain would have to affect loss to follow-up differently in the exposed and unexposed. ${ }^{22}$ Hence, we find it unlikely that selection bias would have distorted our results other than to a minor extent.

In the present study, we considered work exposures to be potential confounders, but they turned out not to confound the associations significantly. However, we cannot rule out the possibility of misclassification of psychosocial and physical work exposure. Another possible explanation to why they were not confounding the associations may be that these factors are not necessarily associated with the levels of disposable income, as defined in our study. We chose not to include education and occupational class as potential confounders due to the risk of over adjusting. Furthermore, a discrepancy in the ability of the participants to recall episodes of neck pain during the previous 5 years may create misclassification of outcome in the study. It

\section{What is already known on this subject}

We know that low income is associated with ill health. We also know that psychosocial factors play an important role in the risk for onset of, as well as the course of, neck pain.

\section{What this study adds}

This study shows an association between income and neck pain specifically. Our findings also suggest that economic stress might be a factor to consider in such associations. These findings support the biopsychosocial model for assessing risk and prognostic factors for neck pain in the general population. would then be likely that they forgot an episode of neck pain thus under-reporting the outcome. However, this possible bias is most likely to be non-differential, occurring to the same extent across income levels.

Another limitation is that changes in income between 2003 and 2007 have not been taken in to account in this study. Some possible explanations to a change of income, such as unemployment or increased salary, are likely to happen in all categories of income and would probably not change the results considerably.

To the best of our knowledge, this is the first study to assess the association between income level and an episode of LDNP. Our findings indicate that low income may be a risk factor, as well as a prognostic factor, for developing LDNP. Furthermore, our results indicate that economic stress may be an underlying factor to consider when studying associations between income and neck pain. Before strong conclusions can be drawn about strengths of such associations, future studies have to address this issue. It would be especially interesting to investigate this in populations with other types of spinal pain and also other types of income levels and social security system.

Contributors All authors contributed to the design of the study and interpreted data. $\mathrm{ML}$ and LP made the statistical analyses. LP wrote the first version of the manuscript. All authors critically revised different versions of the manuscript. All authors read the final version of the manuscript.

Funding The Stockholm Public Health Cohort was financed by Stockholm County Council. The study was supported by grants from the Swedish Council for Working Life and Social Research. The salary for LP was provided by the Doctoral School in Health Care Sciences at Karolinska Institutet, Stockholm, Sweden.

Competing interests None.

Ethics approval Ethics approval was provided by Regional Committee on Ethics at Karolinska Institutet.

Provenance and peer review Not commissioned; externally peer reviewed.

\section{REFERENCES}

1. Hogg-Johnson S, van der Velde G, Carroll LJ, et al. The burden and determinants of neck pain in the general population: results of the Bone and Joint Decade 2000-2010 Task Force on neck pain and its associated disorders. Spine (Phila Pa 1976) 2008;33:S39-51.

2. Cote $\mathbf{P}$, van der Velde G, Cassidy JD, et al. The burden and determinants of neck pain in workers: results of the Bone and Joint Decade 2000-2010 Task Force on neck pain and its associated disorders. Spine (Phila Pa 1976) 2008;33(Suppl 4): S60-74

3. Carroll LJ, Hogg-Johnson S, van der Velde G, et al. Course and prognostic factors for neck pain in the general population: results of the Bone and Joint Decade 2000-2010 Task Force on neck pain and its associated disorders. Spine (Phila Pa 1976) 2008;33:S75-82.

4. Bergstrom G, Bodin L, Bertilsson $\mathrm{H}$, et al. Risk factors for new episodes of sick leave due to neck or back pain in a working population. A prospective study with an 18 month and a three-year follow-up. Occup Environ Med 2007:64:279-87.

5. Holtermann A, Hansen JV, Burr H, et al. Prognostic factors for long-term sickness absence among employees with neck-shoulder and low-back pain. Scand J Work Environ Health 2010;36:34-41.

6. Carroll LJ, Cassidy JD, Côté P. Depression as a risk factor for onset of an episode of troublesome neck and low back pain. Pain 2004;107:134-9.

7. Leijon 0, Wahlström J, Mulder M. Prevalence of self-reported neck-shoulder-arm pain and concurrent low back pain or psychological distress: time-trends in a general population, 1990-2006. Spine (Phila Pa 1976) 2009;34:1863-8.

8. Kosidou K, Dalman C, Lundberg M, et al. Socioeconomic status and risk of psychological distress and depression in the Stockholm Public Health Cohort a population-based study. J Affect Disord 2011:134:160-7.

9. Andersen I, Thielen K, Nygaard E, et al. Social inequality in the prevalence of depressive disorders. J Epidemiol Community Health 2009;63:575-81.

10. Johnson JG, Cohen P. Dohrenwend BP, et al. A longitudinal investigation of socia causation and social selection processes involved in the association between socioeconomic status and psychiatric disorders. J Abnorm Psychol 1999;108:490-9.

11. Marmot M. The influence of income on health: views of an epidemiologist. Health Aff (Millwood) 2002;21:31-46.

12. Aittomäki A, Martikainen $\mathrm{P}$, Laaksonen $\mathrm{M}$, et al. The associations of household wealth and income with self-rated health-a study on economic advantage in middleaged Finnish men and women. Soc Sci Med 2010;71:1018-26. 
13. Lundberg U. [Psychological stress and musculoskeletal disorders: psychobiological mechanisms. Lack of rest and recovery greater problem than workload] (In Swedish). Lakartidningen 2003;100:1892-5.

14. Statistics Sweden. Longitudinal Integration Database for Health Insurance and Labour Market Studies (LISA by Swedish Acronym). http://www.scb.se/Pages/ List 257742.aspx (accessed 15 Nov 2010).

15. Statistics Sweden. FoB (Population and Residence Register). http://www.scb.se/ Pages/List 257507.aspx (accessed 15 Nov 2010).

16. Guzman J, Hurwitz EL, Carroll LJ, et al. A new conceptual model of neck pain: linking onset, course, and care: the Bone and Joint Decade 2000-2010 Task Force on neck pain and its associated disorders. Spine (Phila Pa 1976) 2008;33:S14-23.

17. Carroll LJ, Hogg-Johnson S, Cote $P$, et al. Course and prognostic factors for neck pain in workers: results of the Bone and Joint Decade 2000-2010 Task Force on neck pain and its associated disorders. Spine (Phila Pa 1976) 2008;33:S93-100.

18. Karasek R, Theorell T. Healthy Work: Stress, Productivity, and the Reconstruction of Working Life. New York: Basic Books, 1990

19. Goldberg DP, Gater R, Sartorius N, et al. The validity of two versions of the GHO in the WHO study of mental illness in general health care. Psychol Med 1997:27:191-7.

20. Martikainen $\mathbf{P}$, Adda J, Ferrie JE, et al. Effects of income and wealth on GHO depression and poor self rated health in white collar women and men in the Whitehall II study. J Epidemiol Community Health 2003:57:718-23.

21. Pizzi C, De Stavola B, Merletti F, et al. Sample selection and validity of exposuredisease association estimates in cohort studies. J Epidemiol Community Health 2011;65:407-11.

22. Norell ES. Workbook of Epidemiology. New York: Oxford University Press, 1995 